REVISTA X, Curitiba, volume 14, n.4,p. 135-157, 2019

\title{
IDENTIDADE, GÊNERO E TRANSGENERIDADE: A CONSTRUÇÃO DO SER-MULHER NO VIDEODOCUMENTÁRIO "LAERTE-SE"
}

Identity, gender and transgenerity: a construction of being-woman in the videodocumentary "Laerte se"

\author{
Ana Luiza CORDEIRO - UTFPR ${ }^{1}$ \\ Nívea ROHLING - UTFPR ${ }^{2}$
}

\begin{abstract}
RESUMO: Levando em conta a acepção de que as identidades e os modos de existir são socialmente produzidos a partir de diferentes práticas discursivas, forjando processos de diferenciação dos sujeitos e legitimando o pertencimento a determinados grupos, o presente artigo analisa os discursos sobre o ser-mulher trans* no videodocumentário Laerte-se, considerando as múltiplas vozes que ecoam nessa narrativa multissemiótica. Para tanto, a análise tomou como base os estudos sobre gênero, sexualidade e identidade tais como: Beauvoir (1980), Butler (2001), De Lauretis (1994), Geraldi (2010), Moita Lopes (2013). O gênero documentário é um objeto diverso, tanto em sua roteirizarão - vozes da protagonista, do produtor, do diretor -, quanto em sua composição - imagens, músicas, enunciados, depoimentos, encenações -, fazendo ecoar e entrelaçar diferentes discursos sobre a identidade trans* para um mesmo produto midiático. Os resultados apontam para quatro eixos de centralização: o íntimo, o privado, o profissional e o ficcional - explicitando a construção identitária do ser-mulher trans do sujeito Laerte que transita entre a dualidade masculina-feminina, instaurada e reforçada socialmente, e a manifestação política do (r)existir como trans*.
\end{abstract}

Palavras Chave: Identidade. Gênero. Videodocumentário. Mulher. Transexualidade.

\begin{abstract}
Considering the meaning in which identities and ways of existing are discourses socially produced by the different discursive practices, legitimizing their belongings to determined groups, this article analyzes the discourses of being a trans-woman*, on the video documentary Laerte-se, considering the multiple voices that reverberate on this multiple semiotic narrative. Therefore, this analysis has its basis on the studies of genre, sexuality and identity such as: Beauvoir (1980), Butler (2001), De Lauretis (1994), Geraldi (2010), Moita Lopes (2013). The documentary genre is a diverse object, both in its scripting - the protagonist's voice, the producer's, the director's -, and in its composition - images, music, statements, depositions, performings -, making it reverberate and intertwine different discourses about the trans'* identity for one media product. The results indicate to four centering axis: the intimate, the private, the professional and the ficcional - explaining the identities constructions of being a trans-woman* from the subject Laerte in which transits between the masculine-feminine duality, established and enforced socially, and the political and individual (r)existence.
\end{abstract}

\footnotetext{
${ }^{1}$ Doutoranda Tecnologia e Sociedade - PPGTE/UTFPR. E- mail: ana.luiza.cordeiro@gmail.com

2 Doutora em Linguística - UFSC. E-mail: nivear@utfpr.edu.br
} 
REVISTA X, Curitiba, volume 14, n.4,p. 135-157, 2019

Key-words: Identity. Gender. Video Documentary. Woman. Transexuality.

\section{INTRODUÇÃO}

As identidades são resultado de processos históricos, sociais e culturais e comuns à maioria dos sujeitos pertencentes às sociedades ou comunidades. Frutos de construções coletivas reforçadas e interiorizadas, as identidades manifestam uma ordem sistemática, fruto de interações entre o funcionamento organizacional e as manifestações dos indivíduos, e surgem, se moldam, se transformam, se transmutam, atuando num reflexo responsivo do período social, político e sistemático vigente (MOITA LOPES, 2002). A manifestação e expressão identitária condiz, também, com as liberdades de expressão e democracia, derrubando um pesado manto conservador, patriarcal e moralista que orienta boa parte do comportamento social supostamente adequado.

No percurso histórico, no que se refere à noção de identidade, destaca-se o insistente desdobramento de relações opressoras em torno do sexo biológico, que determina a partir das genitálias quais os comportamentos e designações que cada sujeito deverá manifestar. Em outros termos, historicamente os modos de sociabilidade - quem somos na vida social - são construídos baseados na identificação dos órgãos sexuais, refletindo e ecoando por toda a vida pública e privada.

Ainda que o processo natural ${ }^{3}$ de gestação pertença às mulheres nascidas com um sistema ovulatório saudável, essa característica biológica delineou um importante e maniqueísta processo de opressão feminina, em que mulheres foram vinculadas aos cuidados da família, à maternidade compulsória e enclausurada nos ambientes internos. Ao homem, portanto, delegou-se atividades externas, públicas, profissionais e externas ao lar. Nesse sentido, a figura da mulher foi indexada a certas características, marcas de feminilidade como: delicadas, dóceis, dedicadas aos cuidados alheios, sendo mantenedora da ordem doméstica e responsável pela educação dos filhos. Mais do que isso, o sistema machista e patriarcal subverte o ser-mulher em uma eterna subserviência à apreciação masculina nas mais diversas esferas, logo que, não obstante ao cerceamento social, o ideal feminino é construído e reforçado sob moldes estéticos. Ser

\footnotetext{
${ }^{3}$ Aqui compreende-se natural advindo da capacidade biológica, sem intervenções médicas ou artificiais. Ressalta-se que mesmo mulheres nascidas com sistema reprodutor aparentemente saudável podem desenvolver impeditivos para a gestação, não sendo excluída a necessidade de procedimentos médicos.
} 
mulher é, frequentemente, atrelado à feminilidade, que, por sua vez, é reflexo de uma exacerbação corporal (WOLF, 1996).

Entretanto, esses modos de conceber o exercício da feminilidade têm sido questionados na contemporaneidade. A partir das lutas feministas, gays, queer, em suma, os movimentos de reconhecimento de minorias, a mulher ganhou espaço para, ainda que lentamente, pronunciar suas demandas, anseios, direitos e necessidades. É necessário ressaltar o abismo que se interpõe entre as sociedades, fazendo com que organizações e movimentos estabeleçam pautas diversas, recorrendo às mais urgentes necessidades. Dentro dos movimentos feministas, há concordâncias e afastamentos do que legitima uma mulher, cabendo às vertentes suas acepções e ideologias, a fim de melhor defenderem seus posicionamentos. Porém, como princípio do movimento de mulheres - cis, trans*, héteros, homo ou bissexuais, em suas diversas formas de existir -, o reconhecimento da mulher como ser social, político e igualitário é a bússola fomentadora que possibilita que sujeitos experimentem, flexibilizem e reinventem suas identidades, sendo reconhecidos em seus hibridismos identitários (MOITA LOPES, 2010).

Assim, surgem e emergem novos discursos, produzidos pelos próprios sujeitos que experimentam suas identidades e, também, produções narrativas por meio do olhar do outro - da mídia, dos pesquisadores, dos sujeitos que compõem a diferença. Esses discursos auxiliam nos modos de conceber a identidade e subjetividade alheia, atribuindo características, hábitos e modos de ser para que o pertencimento a determinados grupos seja legitimado socialmente.

A análise fílmica ou, neste caso, videodocumental, é muitas vezes um processo complexo que necessita decompô-lo sem descontextualizá-lo (PENAFRIA, 2009). Portanto, visa, sobretudo, coletar falas e imagens que melhor apreendam o contexto e o enredo, prosseguindo para o esclarecimento dos sentidos estabelecidos. Como sugere Penafria (2009), o processo analítico visa envolver diversos aspectos presentes no objeto analisado, como sons, cores, falas, narrativa e cenas - ainda que estáticas - de modo que possam caminhar aos objetivos do trabalho. Nesse contexto, o presente artigo apresenta uma análise de um videodocumentário intitulado "Laerte-se", com vistas a observar a discursividade sobre o ser-mulher trans*. Para tanto, inicialmente traçamos uma discussão teórica sobre identidade, a seguir, descrevemos aspectos metodológicos e, por fim, apresentamos a análise empreendida. 
REVISTA X, Curitiba, volume 14, n.4,p. 135-157, 2019

\section{IDENTIDADE TRANS* E A MULTIPLICIDADE DO SUJEITO}

A modernidade estoura com uma liberdade dos sujeitos e das individualidades. Uma parcial desconstrução dos parâmetros do ser mulher e do ser homem conseguem transcender a ferrenha supressão identitária dos sujeitos que são ajustados a um sistema opressor (MOITA LOPES, 2010). Ou seja, toda excentricidade é suprimida dentro dos moldes do que é, arbitrariamente, definido como normal. Estar fora dos parâmetros, romper as normas, a moral, a tradição de condutas estabelecidas e reforçadas há décadas é, ao mesmo tempo, resistência, reafirmação identitária e transgressão. Mas é, sobretudo, nesse recente tempo de mudanças que insurge e se fortalece a (r)existência pelo rompimento e diluição do dispositivo binário de gênero que segrega o sujeito. Abrem-se brechas para ser homem e transitar na esfera definida como feminina, assim como é dado à mulher a possibilidade de não corresponder à idealização do ser mulher.

Distanciando-se dos discursos médicos e definições biológicas, os modos de exercer a feminilidade e a masculinidade se misturam, hibridam-se, entrelaçam-se, sendo de suma importância conceber as identidades como resultados de uma complexa rede hiper e transconectada, alterada, composta, influenciada e carregadas de modelações de instituições, sendo elas as religiosas, culturais, morais, temporais, familiares e sócio contextuais (FOUCAULT, 2005). Portanto, os sujeitos não são frutos isolados e assépticos do meio histórico, tendo suas liberdades e deveres moldados pelas suas experiências e vivências, mas também pelo percurso social.

Ainda que o indivíduo seja carregado de um DNA único, não é por mera biologia ou carga genética que ele apresenta sua unicidade no mundo. Uma rede complexa se engendra para resultar num sujeito cultural, social, dotado de subjetividades e, portanto, opositivo ao outro (MOITA LOPES, 2002). Quando se fala de mulheres, homens, homossexuais, transexuais, crianças, brasileiros ou qualquer outra categoria de identificação, é através de uma construção discursiva que se atribui elementos de significação a esses sujeitos. Ainda que as características biológicas como as genitálias - ou regionais - como a localização de nascimento - sejam preexistentes ao indivíduo, é somente pela construção social, hábitos e reforços institucionalizados que se conforma o que o sujeito poderá ser, bem como valida ou invalida o que ele é.

Entre as práticas adotadas ou negadas, as identidades sociais subscrevem um universo amplo e bastante complexo. Ainda que a natureza plural do indivíduo esteja 
coabitando há séculos os ambientes sociais, é especialmente a partir dos anos 2000 que a temática entra em voga e suscita embates mais fervorosos, (MOITA LOPES, 2010). Encobertas pelo manto denso da moralidade, as pautas que permeiam sexualidade e gênero permanecem recusas aos meandros do inexistir. Nega-se a possibilidade e a necessidade de exceder à norma, exclui-se o sujeito que se encontra no limbo do anormal, nega-se, então, a identidade e heterogeneidade da realidade alheia, reforçando os preconceitos de quem reluta em moldar-se em caixas desconfortáveis de uma existência dilacerada.

No que se refere à distinção entre preferência sexual e identidade de gênero, como aponta Jesus (2012), há uma intensa discussão sobre terminologias dentro do movimento LGBTT ${ }^{*}{ }^{4}$. A bandeira da diversidade abrange e explora uma gama muito mais ampla e, por isso, complexa de denominações que imbricam diversas direções identitárias e sexuais opositivas à norma. Como exemplo, tem-se a normatividade do sujeito heterossexual - atraído física e afetivamente pelo sexo oposto - em conformidade com seu gênero de nascença e admitindo os estereótipos designados ao seu gênero - se mulher, feminina, delicada; se homem, viril, macho. Opondo-se a essas conformidades estruturais, têm-se as lésbicas, gays, bissexuais - atraídos pelo mesmo sexo e ambos os sexos, consecutivamente - , os transgêneros - sujeitos que não se reconhecem no gênero atribuído socialmente e reivindicam o tratamento na identidade que estão performando.

No entanto, estudos de gênero, sexualidade e identidades têm ganhado bastante visibilidade e ascendido no meio acadêmico e social, sobretudo como forma de tecer uma compreensão e expressão dos sujeitos (BENTO, 2006). Nesses estudos, entende-se que afragmentação dos papeis e atuações sociais de homens e mulheres se constroem num processo ainda lento de rompimento normativo e descoberta individual, em que as sociedades se baseiam em formas definidas de conceber a existência dos sujeitos. Portanto, existir se debruça na necessidade de ser reconhecido nesses padrões e estereótipos muito mais do que se reconhecer pertencente a eles. Como aponta Silva (2000), pertencimento, reconhecimento e legitimação das identidades se dão na esfera do social, da construção discursiva, de modo que a identidade - aproximação ou diferenciação com o outro -, não é natural, pertencentes à essência humana, e sim a processos históricos, ideológicos e discursivos, que são constantemente reproduzidos e

\footnotetext{
4 Sigla referente a Lésbicas, gays, bissexuais e transgêneros. Seguindo a convenção da ABGLT (Associação de gays, lésbicas e transgêneros), o T* engloba todas as identidades trans.
} 
reforçados, moldando os nichos sociais identitários. Nesse sentido, a "identidade e a diferença se traduzem, assim, em declarações sobre quem pertence e sobre quem não pertence, sobre quem está incluído e quem está excluído" (SILVA, 2000, p. 82).

Entremeando as diversas manifestações e expressões, é através das linguagens corporal, oral, indumentária, cultural e outras que se tece, afirma e consolida um pertencimento ou não a determinados grupos e espaços sociais. Tomando o sistema social como uma construção, um molde artificial que delineia a atuação humana, recaise sobre a retroalimentação estrutural discursiva, em que os discursos constroem, alteram e reforçam os constructos sociais (MOITA LOPES, 2002).

Não obstante, a concepção de sociedade moderna, funcional, ideal é estabelecida em papeis e designações essencialmente discursivas que nada têm de natural. São, ao contrário, fruto de uma racionalização e naturalização da humanidade que desumaniza o sujeito, estipulando uma lógica opressora, em que os indivíduos são parte ínfima da engrenagem. Nesse contexto de práticas sociais e identitárias, analisar as construções discursivas dos sujeitos é, de certo modo, possibilitar abertura e visibilidade a novas narrativas sobre como viver a vida social, dando atenção às formas outras que se constroem realidades e interpretações de mundo a partir da linguagem, portanto, o presente estudo se justifica pela importância em lançar olhares, a partir de uma ancoragem teórica, sobre as produção e circulação de discursos que sustentam as noções de sujeitos e suas formas de sociabilidades. Entretanto, como sugere Geraldi (2010), ainda que haja uma constante (re)apropriação e reprodução dos discursos existentes na sociedade, os sujeitos são sempre únicos e singulares que, ao integrar, participar, coabitar e, portanto, interagir no mundo, produzem respostas.

Não é suficiente que os sujeitos se autoproclamem homens ou mulheres. A discursividade que legitima o gênero é muito mais complexa, densa e enraizada nas tradições e processos de essencialização das identidades e nos processos discursivos constituídos nas relações de alteridade que na enunciação individual. É preciso que todo o entorno social reconheça o sujeito como pertencente ou não ao gênero feminino ou masculino, validando e legitimando o sujeito para ser o que se é (LANZ, 2008). É preciso que sujeitos que se identifiquem como mulher se comportem e esbocem rituais femininos sem causar estranhamento ou deslocamento para o outro. É preciso que sua aparência, hábitos e entonações transitem no universo feminino, de acordo com as definições sociais do que é ser feminina. Nesse sentido, se retoma a noção de que identidades não são definições finalizadas, mas sim processos constantes de construção 
REVISTA X, Curitiba, volume 14, n.4,p. 135-157, 2019

(HALL, 2006). No caso de mulheres trans*, foco da presente análise, quando exercem sua existência de modo público ou midiático, geralmente, há um reforço insistente dos trejeitos de uma mulher irreal, construída no inalcançável, desde sua personalidade afável e doce, até seus corpos padronizados, plasticizados e fetichizados.

Ser mulher sempre esteve social, histórica e enfaticamente relacionado à existência em oposição ao homem, ao sujeito normal e social. Aqui, subentende-se normal como diligente às normas, figura estipulada como verdadeira, válida, reconhecidamente existente, um certo tipo de identidade "mestra". Em meio à normatização e essencialização construída socialmente do binômio mulher/homem, revelam-se os sujeitos que transgridem as regras, quebram a linearidade, constroem e expõem outras narrativas possíveis sobre seu corpo e do exercício de sua sexualidade.

Dessa maneira, transgêneros, travestis, crossdresser, andrógenos e outras identidades subvertem as categorias até então fixas e irrefutáveis do gênero. Para Bento (2010), dar atenção à transexualidade é, sobretudo, manifestar a existência de sujeitos que se percebem inadequados ao gênero que, construído socialmente a partir de características biológicas, lhes foi atribuído. Portanto, a genitália, assim como demais partes do corpo, não é determinante para estabelecer a identidade, livrando-o das concepções masculino/feminino preestabelecidas com base em discursos biologizantes. Admitir a identidade social como uma construção discursiva e social é, de certo modo, abrir uma fissura para romper a incongruência de forçar comportamentos e atuações aos sujeitos a partir de atributos físicos e biológicos é, forçosamente, estipular padrões sistêmicos que jamais serão aceitos em sua totalidade (MOITA LOPES, 2010), logo que cada indivíduo esboça sua unicidade e subjetividade na expressão social que é, frequentemente, suprimida pelos ditames da normatividade.

\section{PERCURSO METODOLÓGICO}

Retomando a noção de que há discursos anteriores aos indivíduos, mas que quando atualizados pelo sujeito compõem sua constituição e apresentação singular na sociedade (SILVA, 2000), buscou-se analisar os discursos sobre ser mulher na narrativa da mulher trans*, no vídeo documentário Laerte-se. A escolha do vídeo documentário dá-se pelo maior distanciamento ficcional, pela amplitude que o gênero permite diante do tema, além da aproximação entre realizadores, colaboradores e o público, visando ainda "incentivar o diálogo sobre diferentes experiências, sentidas com maior ou menor 
REVISTA X, Curitiba, volume 14, n.4,p. 135-157, 2019

intensidade. Apresentar novos modos de ver o mundo ou de mostrar aquilo" (PENAFRIA, 1999).

O documentário caminha numa tênue linha entre o jornalístico - factual, comprometido com a realidade -, e o cinematográfico - ficcional, encenado -, pois ainda que guiado pela retomada histórica ou biográfica, há uma construção, uma narrativa produzida por autores, produtores, cortes de câmera e produção de sentidos (CASTRO, 2005). Então a escolha dos ângulos, a tonalidade das imagens, o ritmo da narrativa, a escolha dos elementos presentes ou ausentes em cena se somam e interferem no resultado, na significação do produto, no direcionamento do olhar do espectador, nos sentidos produzidos por esse objeto audiovisual. No entanto, ainda que haja um produto midiático pautado na representação e refração de uma certa realidade, como uma notícia, ela é o recorte da realidade, construída e reproduzida por um sujeito carregado de valorações, seja ele repórter, produtor, protagonista ou o próprio público.

Para Moita Lopes (2010), a tecnologia atua também como uma força sociopolítica, intensificando e promovendo a disseminação de discursos individuais que são representações da sociedade, muitas vezes, silenciada pela hegemonia midiática. Nesse sentido, a ampliação do acesso aos gêneros ficcionais, cinematográficos e documentais, bem como a maior distribuição comercial desses produtos, promove amplificação dos debates quanto às narrativas e discursividades produzidas, pautadas e disseminadas. Visando observar e analisar as regularidades emergentes no tocante aos discursos sobre a identidade da mulher trans* que se enuncia nesse documentário, foram delimitadas como categorias determinadas esferas (campos) da vida dessa mulher trans*, a saber: a esfera Privada, Pública, Profissional e Ficcional.

A partir dessas esferas de constituição de sua identidade que emergem em sua narrativa, foram selecionadas cenas, imagens que remetem a esses discursos sobre ser mulher trans*. Assim, foram identificados trechos em que há a narrativa da protagonista em sua intimidade, dentro de casa ou no banho, lidando com seu corpo, sexualidade e auto percepção, permeando o espaço do Privado; Laerte se arrumando para sair, escolhendo roupas e discorrendo sobre os modos de se apresentar ao mundo, ao externo, ocupam o Público; em Profissional, há relatos sobre os impactos da transgeneridade no decorrer de sua carreira e influências em sua produção artística. Por fim, cenas em que se apresenta o cenário figurado, organizado e ajustado para a entrevista, para o relato da protagonista diante de perguntas, cinegrafistas e microfones, são atribuídas ao Ficcional. 
REVISTA X, Curitiba, volume 14, n.4,p. 135-157, 2019

\section{LAERTE(-SE): A ENUNCIAÇÃO DE UMA MULHER TRANS*}

O documentário Laerte-se foi tomado como objeto de análise, com enfoque na discursividade sobre ser mulher trans*, observada por meio das falas da protagonista, produzidas no interior do processo de roteirização, recorte e edição dos produtores e diretores do documentário. Laerte Coutinho é uma reconhecida cartunista e chargista brasileira, nascida em 1951 e com diversos trabalhos veiculados em jornais de referência, como Folha de S. Paulo, O Estado de S. Paulo, além de livros, almanaques e folhetins publicados. Iniciando sua carreira em 1970, na Revista Sibila, Laerte somou prêmios e reconhecimento ao longo de sua trajetória profissional ${ }^{5}$, contribuindo, inclusive, com a consolidação das charges nas esferas editoriais e jornalísticas. O processo de percepção e transição de gênero da protagonista foi gradual e apenas por volta dos 60 anos, época de 2010, sua mudança de comportamento começou a ser notada publicamente, iniciando com o crossdresser - termo que designa o homem se vestir de mulher, com acessórios e roupas definidas como femininas -, posteriormente se entendendo como travesti e, finalmente, como mulher trans*, porém ainda sem optar por intervenções cirúrgicas de mudança de sexo.

Assim, frisa-se que a transição de gênero se deu após a ascensão e consolidação profissional de Laerte, em que a sociedade já (re)conhecia sua atuação, existência e pertencimento ao meio profissional dos cartoons e charges antes das temáticas LGBTT* emergirem em sua vida. Portanto, ao referir-se como mulher trans*, a protagonista não é, necessariamente, a representação da maioria das pessoas marginalizadas pelo apagamento identitário. Enquanto o Brasil estampa o título de país que mais mata pessoas trans* no mundo, com altos índices de violência e discriminação, negando uma existência digna, mercado profissional, espaço acadêmico e social de livre trânsito às pessoas trans*, Laerte ocupa um espaço privilegiado na mídia, equilibrando-se no limiar entre uma sociedade resignada e uma sociedade receptiva à sua existência.

O documentário sobre Laerte foi produzido pela TrueLab para a Netflix, sob a direção de Lygia Barbosa da Silva e Eliane Brum. Tem duração de 1h41min, roteiro de Raphael Scire, Lygia Barbosa e Eliane Brum, com a colaboração de Nani Garcia. Lançado em maio de 2017 levou, ao todo, três anos para ser finalizado, alternando entre o acompanhamento da rotina de Laerte, entrevistas, coleta de depoimentos e finalização das imagens e edições. As pausas nas entrevistas formam uma lacuna que é exposta no

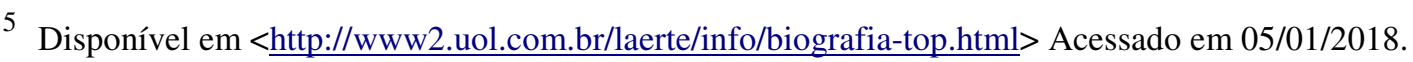


início da narrativa e justificada pelo desconforto de Laerte em se protagonizar midiaticamente, em deixar um público desconhecido adentrar sua casa e sua história. Mais do que a entrevistadora Eliane Brum e os cinegrafistas, ao deixar-se gravar em seu cotidiano, Laerte permite que seu corpo, sua trajetória, suas fragilidades e receios sejam expostos aos mais diversos entendimentos do que possa ser uma trans*, do que não é uma mulher, do que deveria ser Laerte. O documentário, então, não é mais sobre quem é Laerte Coutinho, mas sim sobre a atravessada e complexa existência de Laerte. Nesse aspecto, o direcionamento da edição, cinegrafia e direção são fundamentais para a construção da imagem da personagem, gerando a comoção, empatia e aceitação - ou não - do público. Elaine Brum rompe o distanciamento de produtora e adentra a cena, aparecendo no papel de entrevistadora no decorrer do documentário, expondo alguns dos direcionamentos e interesses advindos do roteiro.

\section{Privado}

A relação corporal é acentuada nos debates sobre transgeneridade (MOITA LOPES, 2013), logo, o corpo é, em geral, o modo dos sujeitos se disporem no mundo, se apresentarem, se pertencerem, se identificarem. A materialidade do corpo é relativamente modificável e praticada pela maioria dos sujeitos através de roupas, cortes de cabelo, brincos, maquiagens, depilação, modificações corporais, tratamentos estéticos e outras possibilidades. Existem, no entanto, determinados estereótipos que se atrelam ao binômio homem/mulher, fazendo com que a adoção de comportamentos ou hábitos, ainda que íntimos, sejam pautados como pertencentes ao universo masculino ou feminino. Ao assumir-se na transição para o universo da mulher trans*, Laerte adota e reproduz atos que designam essa nova identidade, como se verifica na Imagem 1, em que Laerte toma banho e utiliza uma lâmina depilatória rosa para raspar as pernas: 


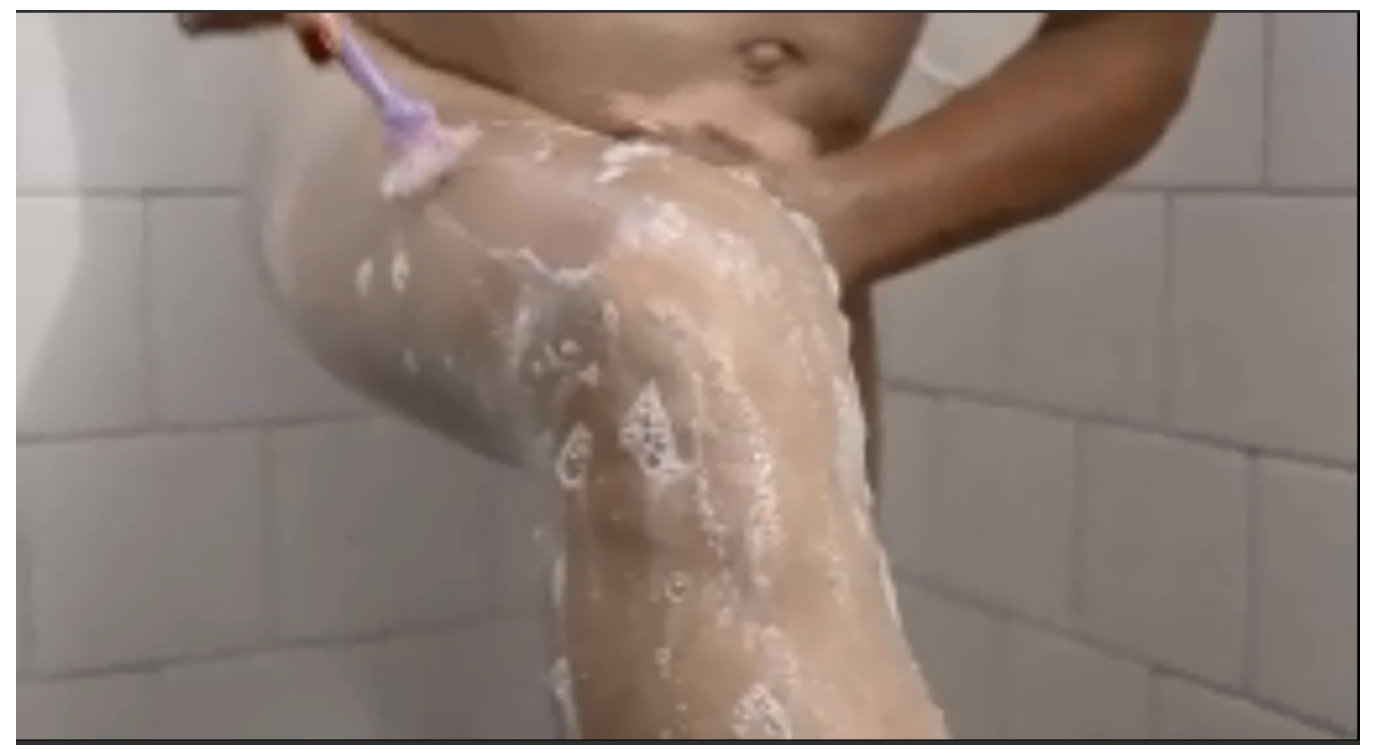

Imagem 1 - Laerte-se

Fonte: Laerte-se; Netflix

A cena em tela remete a uma necessidade naturalizada da mulher se livrar dos pelos numa ânsia higiênica, em que, apesar de componentes naturais de proteção biológica, eles adjetivam pejorativamente quem decide mantê-los. Empunha-se uma construção machista diante da naturalidade do corpo feminino, reforçando no imaginário social a estética do corpo liso, depilado e, inclusive, infantilizado, que recobra a essência feminina pura, infantil e vulnerável. Pode-se, ainda, tomar a depilação como um anseio (in)consciente de fragilizar, inibir a mulher, logo que os pelos que recobrem o corpo o deixam menos exposto - ao frio ou aos olhares.

Não obstante, a lâmina utilizada é rosa, remetendo às atribuições sexistas de gênero. A cena traz o choque simbólico dos hábitos, em que lâminas são publicamente para barbear, produtos destinados ao público masculino, enquanto mulheres adaptam-na para suas necessidades sem que vertam para o consumo feminino. Assim, faz-se necessário segregar os consumidores através de personalização do produto, lançando lâminas cor-de-rosa para torná-las socialmente aceitas para o consumo feminino ${ }^{6}$. Neste aspecto, ainda que a mulher trans* utilize o produto que antes já fazia parte de seus hábitos no universo masculino, ele precisa ser repaginado, remetido ao ser mulher, ao corpo da mulher. Depilar-se com uma lâmina rosa é, possivelmente, um modo de transpor ao corpo o que Laerte viveu internamente: despir-se da aparência de homem,

\footnotetext{
${ }^{6}$ Segundo pesquisa americana, produtos destinados ao público feminino custam em média $7 \%$ a mais que os mesmos destinados ao público masculino. Não diferenciação de marca, funcionalidade ou tamanho, apresentando apenas cores e estampas como diferencial. Disponível em <http://www1.nyc.gov/site/dca/partners/gender-pricing-study.page> Acesso em: 10/01/2018.
} 
atribuir-se de objetos e adereços femininos e deixar-se ver. Sem pelos, nu, exposto aos olhos alheios.

Articulando com a categoria de corpo/percepção corporal dada na Imagem 1, se ressalta a fala de Laerte, no minuto 34'” 55', “eu tô ousando fazer uma coisa que tava no campo das proibições, né: não mexa no seu corpo”. A concepção de mexer, alterar o corpo, dada por Laerte é tida estritamente como cirúrgica, já que ela explana sua intenção de colocar próteses de silicone. Embora a cirurgia seja amplamente mais invasiva que a prática de depilação, ambas se situam na esfera de que há um simbolismo no ser mulher intrínseco ao corpo físico, altamente valorado no reconhecimento material da mulher. Em outras palavras, ainda que haja corpos femininos sem maquiagem, não depilados, sem volume mamário, é a partir destes e de outros referentes que se constrói imageticamente a mulheridade.

Sequencialmente, no 36', Laerte questiona as motivações desta legitimação da mulher pelo corpo, "eu sou uma mulher sem hormônios, sem quadril. Se a ideia tá factível para mim, por que eu preciso de peitos?”. Logo, recobra-se o princípio do que é, de fato, ser mulher, ser um corpo feminino, ser uma mulher trans* buscando alinhar sua imagem aos seus desejos de perceber-se satisfeita mental, emocional e corporalmente. Quando a protagonista verbaliza seu maior motivador para realizar a intervenção cirúrgica, desponta a lógica machista da utilização do corpo feminino: "não quero seios para exercer uma vida sexual. Tô pensando no valor simbólico. Quero seios para tê-los, para vivê-los".

Laerte apresenta seu desejo em submeter-se à cirurgia de colocação de próteses, atentando para a experimentação através do corpo de sua identidade, mas não necessariamente de sua sexualidade. Os seios são interpretados como atributo da mulher, uma peça de seu poder sedutor e, por isso, bastante fetichizado. Ainda que os seios representem uma área erógena e de grande prazer às mulheres ou, ainda, elo na amamentação para a relação maternal, eles são geralmente carregados de valoração masculina, recaindo à estética ou a proporcionar prazer alheio. Especificamente na fala em destaque, Laerte aponta sua abstenção na busca pelo seu prazer, sua satisfação sexual está suprida, restando aos seios apenas a conformidade corpórea.

As roupas, as formas físicas, o comportamento, tudo é atribuído de significação. A própria protagonista explana sua percepção quanto ao funcionamento social: "Esse modo falsamente masculino de se apresentar ele não é despretensioso", pois esse modo articuladamente de destinar as mulheres à sutileza, à submissão, o empenho de construir 
REVISTA X, Curitiba, volume 14, n.4,p. 135-157, 2019

exaustivamente imagens afáveis e dóceis de si mesmas não é, de modo algum, desconectado da vontade de manter o status quo. Portanto, como Laerte reflete, a construção da masculinidade vigora no imaginário do homem vil, forte, e que não é um fato aleatório, mas sim carregado de pretensões hierárquicas. Gerações passam e mulheres continuam sendo incessantemente cerceadas por supostas necessidades socialmente construídas. Como aponta Wolf (1996), a beleza é, portanto, um mito construído e instituído por homens, sendo alcançado, muitas vezes, por meio de artifícios como roupas, acessórios e maquiagens. E como construção social, o mito - o belo e o estético —, é um modo de se apresentar ao mundo, discursos que opõem ou consolidam as identidades (MOITA LOPES, 2002).

Entre as falas que se tecem no decorrer do documentário, é frequente o intercalar do sujeito Laerte em suas tarefas cotidianas e o sujeito Laerte em suas falas políticas. Ainda que nenhuma ação seja despretensiosa, sobretudo para os indivíduos que desafiam as normas sociais, constitui-se uma tessitura verticalizada do que é ser uma mulher trans* aos olhos de Laerte. Entre se perceber e se aceitar mulher trans* entre escolhas de vestidos e maquiagens, há noção de uma imensidão sócio histórica na constituição dessa identidade bastante visível nas falas da protagonista: "As mulheres estão no mundo deles. Então elas têm que tomar cuidado e prestar atenção”. Laerte expõe a consciência de que o mundo é modelado em referência aos homens. É uma naturalização do masculino que impregna o poder e dominação masculina, fazendo ressoar o machismo insuportável e insustentável na sociedade, corroborando com a ideia de que, ainda que as mulheres tomem "[...] parte na elaboração do mundo, esse mundo é ainda um mundo que pertence aos homens" (BEAUVOIR, 1949, p. 21).

Ainda quanto à fala destacada, há também a escolha dos elementos linguísticos para a designação dos sujeitos e estruturação do enunciado, em que Laerte fala das mulheres na terceira pessoa, afastando-se discursivamente, ainda que de modo inconsciente, da identidade mulher, podendo pressupor que ainda há a manutenção de um vínculo com o mundo, com as possibilidades e com os privilégios masculinos: "As mulheres estão no mundo deles". Porém, exaltando a consciência que ser mulher é não pertencer ao mundo que, por direito, é dos homens, e que ser mulher trans* é abandonar, ainda que em partes, a vivência do sujeito homem, Laerte admite que o mundo não é mais seu também. 


\section{Público}

Laerte, ao enunciar "Fiz algo que demorei sessenta anos para fazer", manifesta sua resistência à mudança, à aceitação do eu que não condiz com a norma, com o esperado, com o que foi naturalizado, sendo um homem que não deseja vestir-se de homem, comportar-se como homem, valer-se de sua masculinidade. Para a mulher trans*, vestidos e saias, saltos e maquiagens carregam a exteriorização do sentimento de ser mulher, compartilhar e usufruir do sentimento de feminilidade. Portanto, Laerte aponta que teve toda sua formação pautada na educação e bases sexistas de uma sociabilidade que lhe negou os adornos e vestimentas femininas. No entanto, seu desejo persiste, seu conforto não condiz com os ternos e sapatos masculinos. Sessenta anos foram necessários para encorajar um sujeito a transgredir os manuais de gênero, de aparência, de vestimenta. Manuais e estereótipos estes que, efetivamente, não existem na identidade da mulher, mas são inseridos no imaginário social.

Após sessenta anos se enquadrando desajustadamente no universo masculino, Laerte agora se permite vivenciar a liberdade de suas escolhas, seja na construção de sua imagem, seja na denominação de gênero. Como segue na Imagem 2, a protagonista opta por roupas que melhor condizem com sua identidade e bem-estar, como vestidos e saias, mas que são, na maioria das sociedades, negados ao gênero masculino, ainda que, atualmente, haja um lento movimento de extensão dessas peças aos homens.

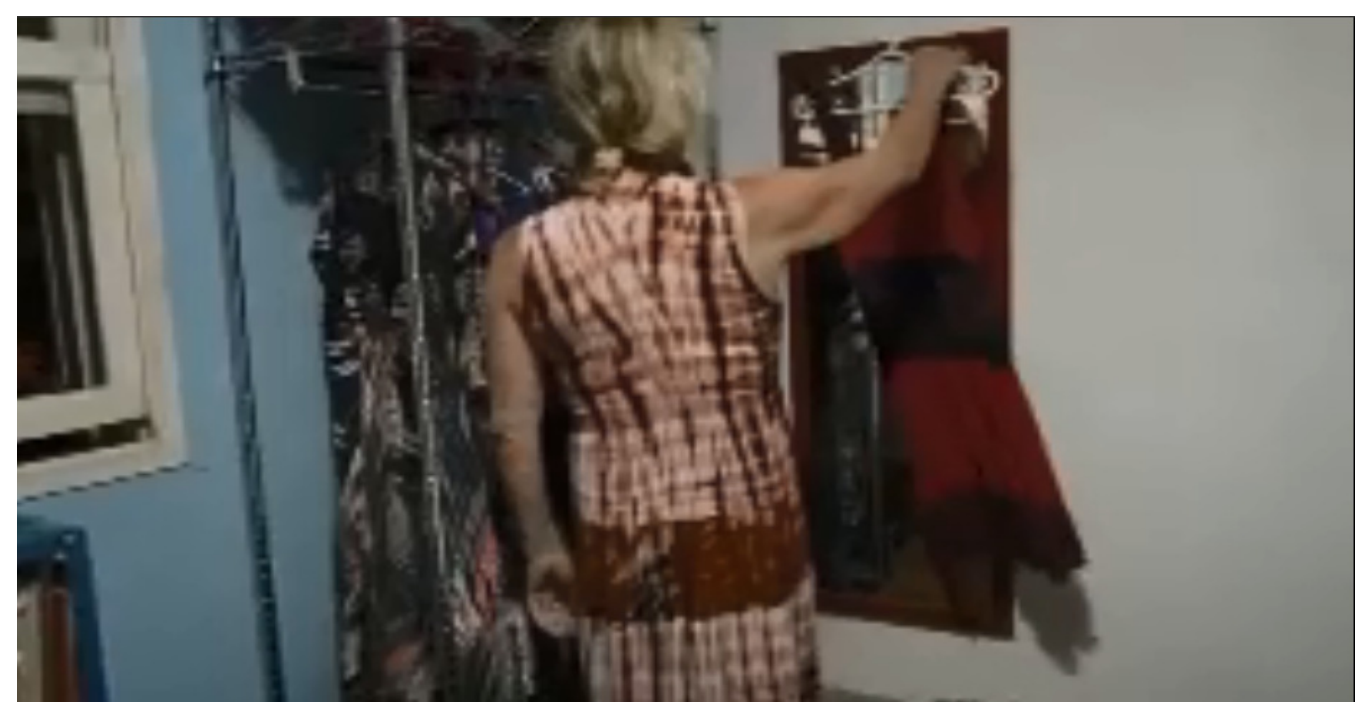

Imagem 2 - Laerte

Fonte: Laerte-se; Netflix 
Na cena acima, minuto 22', Laerte discorre sobre o conforto de se sentir livre para escolher as peças de roupas, independentemente do suposto gênero da peça. Sabese, a priori, que há uma dualidade na confecção, produção e comércio de roupas e acessórios, que há também uma segmentação mercadológica que distingue homens e mulheres na comercialização indumentária, mesmo para aquelas peças em que não há necessidade de separação entre feminino e masculino. Mesmo que existam culturas em que homens vestirem saias seja considerado aceitável, o contexto social brasileiro, ainda baseado em ditames tradicionais, assume como pejorativa a transição ou adoção de comportamentos atribuídos ao sexo oposto. Ao abandonar sua denominação e pertencimento ao universo masculino e adentrar as vivências crossdresser, travesti e, no momento da produção do documentário, transgênero, Laerte se permite adotar saias e vestidos como condizentes com a identidade que está assumindo, sem que haja uma ruptura da aparência com as pressupostas socialmente.

Em suma, os estereótipos de gênero sugerem que homens vistam calças e mulheres vistam saias, incluindo aqui os sujeitos desviantes, como homens e mulheres trans*. Há, portanto, um confronto parcial das normas e padronizações, pois se retoma comportamentos antecedentes, reforçando imagens e ideais plásticos do que é ser mulher. A escolha das roupas e modo de se apresentar implica na categoria Público por ser o modo como Laerte se enxerga e decide se apresentar ao mundo. Ainda que carregada de pessoalidade, a construção identitária a partir do corpo é um caminhar delicado entre o íntimo e o público, logo que é perante essa exposição da materialidade corporal que se constitui, também, o diálogo com o outro. O corpo, sua apresentação, sua modelação e personificação são extensões do modo de conceber o mundo, maneiras que o sujeito se posiciona em relação ao que ele é e ao que o mundo lhe oferece de possibilidades de ser (GERALDI, 2010). A materialidade corporal é, portanto, um emaranhado de significações e simbolismo, uma construção multissemiótica que resulta em formas de agir e (r)existir no mundo.

No documentário, ressalta-se ainda, há 7 cenas em que se faz referência objetiva à estética e à corporeidade através do que é visualmente apresentado, sendo elas nos minutos 23', 24', 29', 37', 55', 1:02', e 1:20', compondo cenas em que Laerte escolhe roupas - que, em geral, são confeccionadas com atribuições de gêneros: roupas femininas ou masculinas -, se maquia, se depila e faz as unhas - hábitos ou cuidados ainda fortemente atrelados ao universo feminino. Enquanto, em 1:14', Laerte dimensiona o impacto das estereotipias femininas em sua vida pessoal e profissional: 
REVISTA X, Curitiba, volume 14, n.4,p. 135-157, 2019

"Eu tô me descobrindo, descobrindo novas formas de expressão. São vestidos novos, sapatos incríveis. Toda hora tem novidade, então isso... é evidente que isso ocupa uma centralidade em meu modo de ser e também no meu trabalho".

Para tanto, durante todo o documentário são entrelaçados recortes da vida pessoal e profissional, mostrando as mudanças ocorridas em suas inspirações, expressões e personagens ao longo, sobretudo, dos anos 2000, quando Laerte assumiu publicamente sua transição identitária. Posteriormente, quando questionada por Elaine Brum se um corpo pode ficar completo, Laerte conclui que o corpo, assim como o trabalho, não se finda, não se completa, pois está sempre em transformação, em adaptação. Como aponta Geraldi (2010), é na tensão dos (des)encontros entre o $e u$ e o outro que se constitui o sujeito, mas essa constituição é frequentemente atualizada, modelada, repaginada pelos diversos outros que atravessam a existência de um sujeito, portanto ele nunca está, de fato, completo. Há, nessa fala de Laerte, uma certa consciência do inacabamento do sujeito, que está sempre se fazendo, se constituindo identitariamente nas relações de alteridade.

\section{Profissional}

A consolidação da carreira profissional de Laerte deu-se antes do processo de transição, de aceitação de sua não identificação com o universo masculino. Assim, ressalta-se que há uma dualidade na constituição do sujeito Laerte Cartunista, em que primeiramente há a conquista do espaço profissional na sua condição de homem. $\mathrm{Ou}$ seja, Laerte permeia as esferas delegando-se, ainda que internamente desconfortável, como homem. Valendo-se de sua posição de homem e consequentemente das condições favoráveis que isso implica, a protagonista consolida a carreira antes de adentrar no turbulento mundo da transição de gênero, antes de erguer a bandeira LGBTT*, antes de ter suas habilidades e capacidades pré-julgadas por questões identitárias e pessoais.

Sabendo que os indivíduos, mesmo que assumindo posturas bastante distintas entre seus papeis e atuações sociais, não são absolutamente capazes de dissociar suas identidades, como pessoal, profissional, familiar, nota-se a refração da transitividade de gênero nos cartoons de Laerte. A protagonista manifesta: "A CASA É UMA $B A G U N C ̧ A$ ”, e exalta como o sujeito se transpõe e se mostra no mundo, atribuindo uma interdependência de sua bagunça interna à bagunça da casa. Aqui, bagunça interna pode ser lida tanto como conflitos internos, descobrimentos identitários, mudanças pessoais, 
como na desorganização proveniente da própria profissão ou estilo de vida adotado por Laerte.

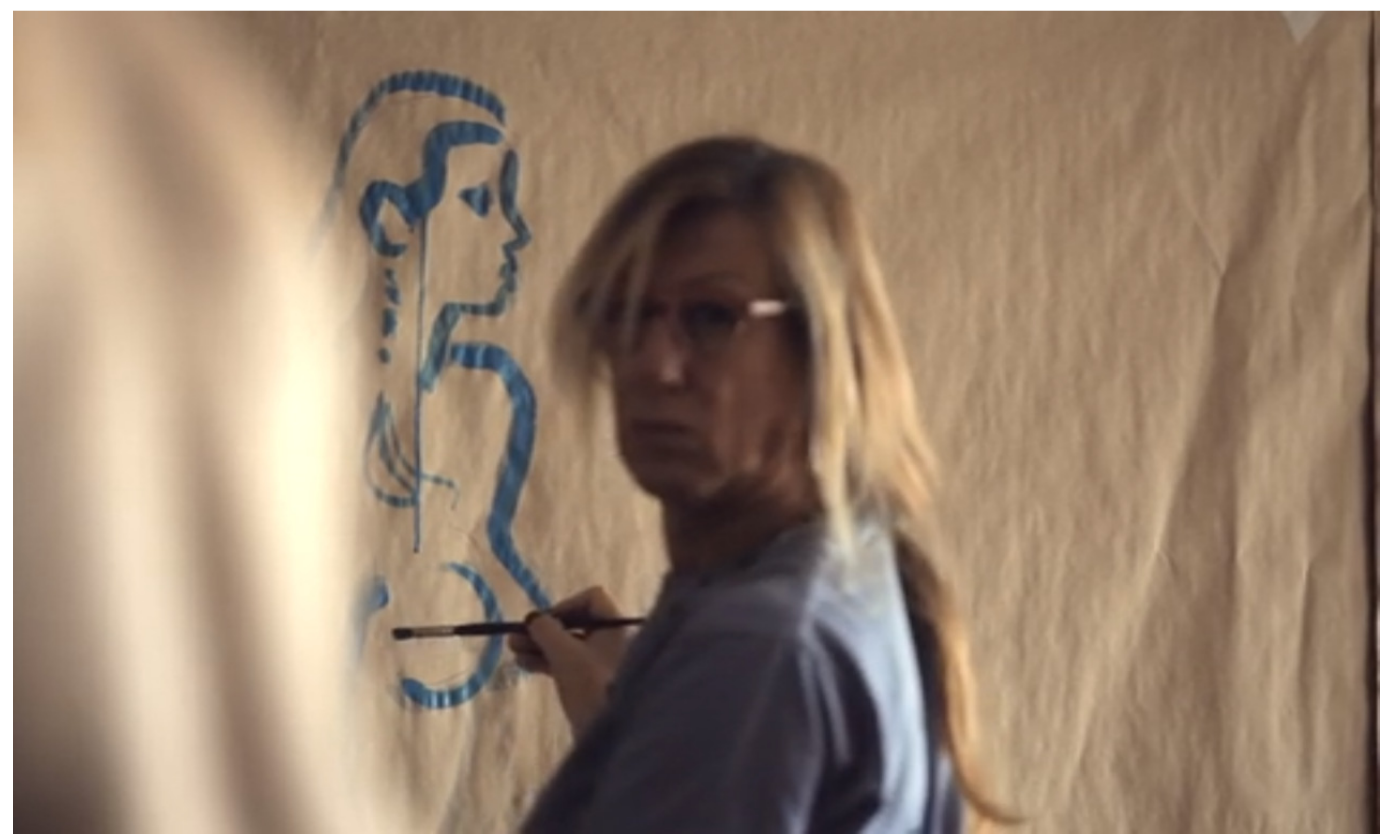

Imagem 3 - Laerte

Fonte: Laerte-se; Netflix

Cartunista, chargista e artista, ela experiencia a inconstante onda de produção e bloqueio criativo próprio de quem trabalha na área de comunicação, criação, artes e crítica social. No que advém das questões internas, num mundo caracterizado por uma polaridade de gênero, em que os ditames binários são fortemente reproduzidos, fazendo ressoar um constrangimento ou inadequação de quem não se enquadra ou não aceita se enquadrar neles, a fala de Laerte sugere um sentimento de exílio social. Um sujeito que reverbera as inadequações de um sistema falido, mas que sofre com o próprio julgamento - consciente ou não - de caminhar fora da norma. Os indivíduos que se percebem desviantes dos preceitos estéticos ou comportamentais socialmente arregimentados, podem carregar a percepção de que estão desajustados ao mundo, às regras, ao funcionamento orgânico da sociedade. Entre reverberar sua (r)existência e exaltar suas vivências como ato político, ou forçar-se aos moldes da sociedade, Laerte e demais indivíduos aportam o sentimento de serem eles mesmos o ponto fora da curva, carregados de uma interpretações, muitas vezes, negativas-depreciadas.

Já no que tange às esferas artísticas e profissionais, as inadequações são frutos de mentes aceleradas, críticas, inconformadas com a realidade. Por isso, os tons ácidos e humorísticos de seus cartuns. Por isso, também, a casa bagunçada, desajustada à 
conformidade, à linearidade de um lar sistemático, pois sua rotina de criação e produção não condiz com a rotina da maioria de outros profissionais.

\section{Ficcional}

Expõe-se, com a imagem 4, uma contraposição, um confronto semiótico na construção visual do ser mulher. Ao lado esquerdo, Eliane Brum, entrevistadora e responsável pela construção do documentário Laerte-se. Enquanto Elaine veste calças jeans e senta-se despojada no sofá, com as pernas encolhidas e os pés descalços, ao lado direito, Laerte senta-se de pernas cruzadas, sapatos de salto e saia curta.

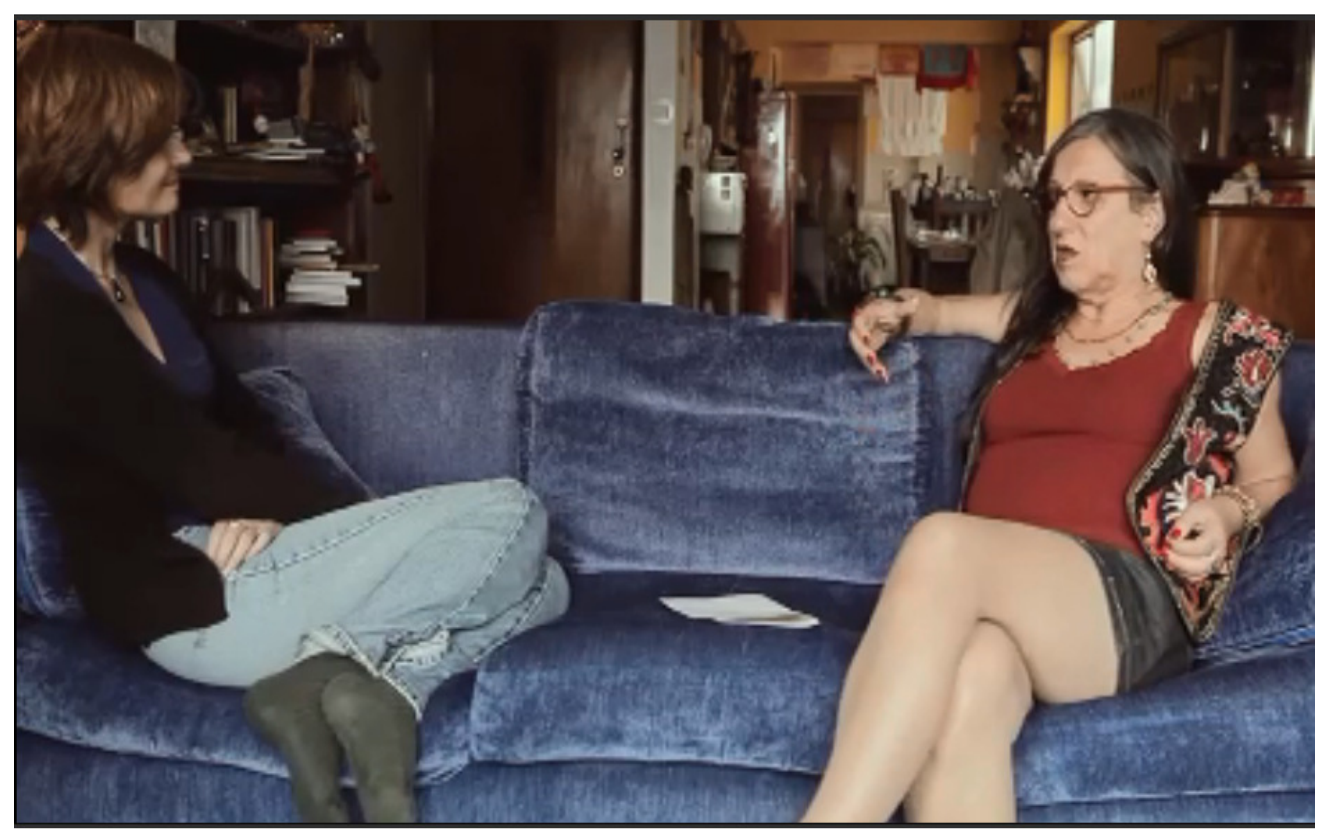

Imagem 4 - Laerte e Elaine Brum

Fonte: Laerte-se; Netflix

Eliane Brum tem cabelos curtos, a postura levemente irregular e curvada, sua maquiagem estampa menos cores, aproximada de uma aparência mais natural ${ }^{7}$. Já Laerte, por sua vez, tem seus cabelos compridos, unhas feitas e as cores que disputam seu corpo são vivas, intensas. Por um lado, pode-se assumir que a aparência de Elaine Brum é planejada para dar destaque à entrevistada, logo que manuais de jornalismo sugerem que entrevistadores devem se comportar e se vestir de modo neutro, visando guiar a atenção do público para o fato, a notícia, o tema (MARTELLI, 2006). Por outro lado, assumindo como não planejada e corriqueira a roupa e o cenário exposto, se tem

\footnotetext{
${ }^{7}$ Natural, neste artigo, é tomada a partir da denominação dos manuais de telejornalismo, em que a maquiagem é aplicada para naturalizar a aparência em frente a câmera, dando opacidade e fazendo correções à pele.
} 
uma contraposição entre duas mulheres presentes em cena. A postura de Laerte não é tão relaxada e as marcas de uma feminilidade imposta são fortes. Enquanto mulheres são inseridas no universo da mulheridade desde que se identifica o sexo do bebê, travestis e transgêneros precisam construir e reafirmar as identidades numa máxima instância. Mais do que ditar-se homem ou mulher, pessoas trans* necessitam do reconhecimento e validação social. Neste aspecto, Jesus e Marques Filho (2012) apontam que mulheres trans* acabam construindo suas imagens no conceito de mulher hiper-real, utópica, idealizada no imaginário social, tendendo à exacerbação da sexualidade, do fetiche e da sensualidade, beirando a um indivíduo caricato, que acaba por tornar simplista a definição do ser-mulher, negando a existência política, individual, subjetiva da mulher, tornando-a um ser reduzido ao corpo estético, a um subproduto esvaziado historicamente. Essa encenação do ser mulher é, então,

[...] puramente uma representação, um posicionamento dentro do modelo fálico de desejo e significação; não se trata de uma qualidade ou de uma propriedade da mulher. O que significa dizer que a mulher, como sujeito do desejo ou da significação, é irrepresentável, a não ser como representação (DE LAURETTIS, 1994, p. 230).

Considerando que a entrevistadora guiou a conversa de modo roteirizado, e que a cena, apesar de ser gravada na casa de Laerte, é uma composição cinematográfica, alterada pelo recorte do cinegrafista, pelas intenções do roteiro, pelo olhar da produção, há a exposição de Laerte figurando a mulher trans* que se tem construída no imaginário social, remetendo à noção de mulher feminina, corporalmente adequada aos padrões construídos socialmente do que é ser mulher e de como exercer as marcas de feminilidade. A Imagem 4, portanto, se situa na esfera ficcional por ser uma cena articulada para a melhor captação do documentário. As posições são encenadas e programadas para ficarem bem enquadradas, os tons de voz são testados e equipamentos de luz e áudio são posicionados, mesmo que não apareçam em cena. Há um roteiro bem marcado nesse momento, mesmo que ele seja semiestruturado, logo que Elaine, como entrevistadora, já sabia como conduzir a entrevista ou, ao menos, quais temas daria enfoque se considerarmos a aplicação de entrevistas semiestruturadas (TRIVIÑOS, 1987).

\section{CONSIDERAÇÕES FINAIS}


REVISTA X, Curitiba, volume 14, n.4,p. 135-157, 2019

Giddens (2005) sugere que a biologia seja uma parte constituinte, porém moldável e alterável dos sujeitos, sendo necessário que o corpo se conceba como instrumento da essência, modificável, espelho da identidade e da construção interna. Assim, o autor desatrela o determinismo dado pelas genitálias e reforça o transitar entre as possibilidades de constituir-se no mundo, logo que "o corpo humano e a biologia não estão dados, mas estão sujeitos ao agenciamento humano e às escolhas pessoais no interior de diferentes contextos sociais" (GIDDENS, 2005, p. 106).

Corroborando com essa noção, Butler (2001) aponta que mais do que a genitália, são as configurações culturais que aprisionam ou concedem liberdades aos sujeitos. A pós-modernidade flexibilizou as afirmativas do que é ser homem e ser mulher. Se as percepções, identidade e papéis sociais de cada sujeito eram, até pouco tempo, estruturas razoavelmente sólidas, atribuindo um futuro determinista já no nascimento ou ainda na ultrassonografia, ao descobrir o sexo da criança - essa imposição começa a ser discutida e questionada. Atentar para o fato de se perceber deslocado e desconfortável no que é estipulado ao indivíduo, em suas múltiplas esferas de identidade, apenas recobra a inadequação do sistema social que persiste em ditar existências, comportamentos e atuações fechadas, simplistas, delimitadas para sujeitos que são múltiplos, híbridos, diversos e inexplorados. As identidades não se finalizam, não se excluem, não se solidificam (GERALDI, 2010). Elas se somam, transpõem, invadem os sujeitos, formam personalidades, alteram as percepções, as vivências, as interpretações, atravessam as formulações sociais e ecoam no espaço sócio histórico.

No documentário analisado, os estereótipos sobre ser mulher emergem e elucidam um importante aspecto sobre as identidades, em que o confronto do que se é ainda está ancorado nas concepções estéticas e comportamentais. Mulheres trans*, muitas vezes, tendem a reforçar ou serem retratadas por meio de aspectos e estereótipos que afligem, oprimem e cerceiam outras mulheres, logo que comportamentos atribuídos às mulheres são, em geral, frutos de construções patriarcais e machistas. Cai-se, então, num problema de reconfiguração social, e não dos indivíduos. $\mathrm{O}$ ato falho, neste aspecto, é mantido pela estrutura, pelos moldes sociais que reforçam o binômio fêmea/macho e suturam a opressão, tornando cada vez mais complexa e exaustiva a renúncia dos comportamentos sexistas, logo que não há uma mulher a ser performada, nem um padrão designado correto para ser mulher. Mais do que isso, numa existência política da mulher e da mulher trans*, torna-se essencial debater a existência do sujeito 
apregoado às reproduções normativas, logo que os sujeitos são múltiplos, híbridos, alternantes, e nunca compostos de uma essência feminina/masculina plena.

Numa sociedade que ainda é facilmente escandalizada pelo rompimento de normas que sequer confluem e se adequam à multiplicidade, sujeitos que dissuadem os padrões, sobretudo mulheres e homens trans*, acabam por assumirem a máxima significação de corpo político. Mais do que compactuar e participar da luta política e social, eles têm a luta simbolicamente estampada no corpo. Então cabe ao sujeito encorajar-se e exercer como ato de resistência, enquanto a estrutura social ainda atua e se encaminha com as definições essencialistas que compreendem as identidades como fixas, imutáveis, inalteráveis. Cabe às pessoas trans* um caminhar denso e atribulado entre as normas que incidem em sua biologia e os acusam de serem desajustados às identidades. Um corpo desviante que se insere no escândalo, no bizarro, no desajuste de uma linearidade que se naturalizou, mas não é natural. Mais do que um conglomerado de células, uma essência subjetiva, uma materialidade do sujeito, o corpo é um ato político, uma forma de (r)existência numa sistematização que apaga o outro.

Não cabe, no entanto, somente aos sujeitos trans* se sentirem desajustados às normas estabelecidas. A feminilidade e masculinidade são resultados de um discurso instaurado e reforçado continuamente, que apregoam estereótipos físicos - como musculatura, tamanho dos cabelos e unhas -, comportamentais - como delicadeza, submissão, tom de voz, agressividade -, e pessoais - como preferência de cor, esportes, aptidão profissional. Portanto, mulheres e homens que, mesmo em conformidade com seu sexo, podem experimentar a não aceitação do sistema cerceador. Mulheres não femininas, que recusam maquiagens, saias ou comportam-se agressivamente são vistas como desviantes, assim como homens que demonstram interesses por cuidados do lar, tratamentos estéticos ou passividade, por exemplo. Mulheres e homens empunham-se contra a naturalização e homogeneização identitária, do apagamento de suas existências e preferências, do sucumbir ao sistema para pertencer a ele. Afirmar-se resistente é, por fim, retomar o controle e autonomia de seus corpos e expressividades, atuações e desejos, é fazer de seus atos e de sua materialidade uma construção discursiva política.

Debater as posições que adotam os sujeitos e grupos sociais faz-se necessário e sobrepujante. Ainda que os debates abalem os alicerces nem tão sólidos de uma construção remendada por utopias, debater questões elucidadas pelo feminismo, transativismo e movimentos identitários é aprofundar o reconhecimento de pluralidades, 
REVISTA X, Curitiba, volume 14, n.4,p. 135-157, 2019

heterogeneidades e uma amálgama composicional que torna o homem capaz de ser exatamente o que se é, um ser único.

\section{REFERÊNCIAS}

BEAUVOIR, Simone. O segundo sexo. Rio de Janeiro: Nova Fronteira, 1980.

BUTLER, Judith. Corpos que pesam: sobre os limites discursivos do sexo. Trad. Tomaz Tadeu da Silva. In: LOURO, Guacira Lopes (Org.). O corpo educado. Belo Horizonte: Autêntica Editora, 2001. p. 151-172.

BENTO, Berenice. A reinvenção do corpo: sexualidade e gênero na experiência transexual. Rio de Janeiro: Gramind, 2006.

CASTRO, Guilherme. Documentário, realidade e ficção. Revista AV-Audiovisual, São Leopoldo, jan.-jun. 2005

COSTA, Marisa Vorraber. Sobre a contribuição das análises culturais para a formação de professores no início do século XXI. Educar em Revista, $\mathrm{n}^{\circ}$ 37, agostodezembro/2010, Curitiba, PR: Editora UFPR. Dossiê: As dimensões formativas do ensino superior no século XXI: a retomada do sentido democrático na formação inicial e continuada dos profissionais da escola básica.

DE LAURETIS, Teresa. A tecnologia do gênero. FUNCK, Suzana. (trad.). In: HOLlANDA, H. (Org.). Tendências e impasses: o feminismo como crítica da cultura. Rio de Janeiro: Rocco, 1994. p. 206-242.

DEL PRIORE, Mary. Corpo a corpo com a mulher: pequena história das transformações do corpo feminino no Brasil. Editora SENAC. São Paulo, 2000.

FOUCAULT, Michel. Em defesa da sociedade: curso no College de France (19751976). São Paulo: Martins Fontes, 2005.

GERALDI, João Wanderley. Sobre a questão do sujeito. In: GERALDI, João Wanderely. Ancoragens: estudos bakhtinianos. São Carlos (SP): Pedro \& João Editores. 2010. p. 103-131.

GIDDENS, Anthony. O que é sociologia . $4^{\mathrm{a}}$ Ed. Porto Alegre: Editora Artmed, 2005.

HALL, Stuart. A identidade cultural na pós-modernidade. São Paulo: DP\&A. 2006.

JESUS, Jaqueline Gomes; MARQUES FILHO, Adir. A mulher hiper-real e outras mulheres no imaginário e no corpo feminino trans. In: II Encontro Nacional de Pesquisa em Moda, 2012, Goiânia/GO. Moda: experiência criativa. Goiânia/GO: FAV/UFG, 2012. v. 1. p. 259-275.

LOURO, Guacira Lopes. Gênero, sexualidade e educação: uma perspectiva pós estruturalista. Rio de Janeiro: Vozes, 2004. 
MARTELLI, Regina. A cara da moda na televisão. Reportagem disponível em $<$ http://noticias.orm.com.br/noticia.asp?id=147439\#.Wnm0GfbJ3kM $>$ Acessado em 06/01/2018.

MOITA LOPES, Luís Paulo da. Gênero, sexualidade, raça em contextos de letramentos escolares. In: MOITA LOPES, Luís Paulo da. (org.). Linguística Aplicada na modernidade recente. São Paulo: Parábola, 2013, p.225-247.

MOITA LOPES, Luiz Paulo da. Identidades Fragmentadas: a construção discursiva de raça, gênero e sexualidade em sala de aula. Campinas, SP: Mercado das Letras, 2002.

PENAFRIA, Manuela. O filme documentário: história, identidade, tecnologia. Lisboa: Cosmos, 1999.

PENAFRIA, Manuela. Análise de Filmes: conceitos e metodologia(a). VI Congresso SOPCOM, 2009.

PRECIADO, Beatriz. Multidões queer: notas para uma política dos anormais. Revista Estudos. Feministas. 2011, vol.19, nº 1, p. 11-20.

SILVA, Tomaz Tadeu da. A produção social da identidade e da diferença. In: SILVA, Tomaz Tadeu (Org.). Identidade e diferença - A perspectiva dos estudos culturais. 14 ed. Petrópolis, RJ: Vozes, 2014, p. 73-102.

TRIVIÑOS, Augusto N. Silva. Introdução à pesquisa em ciências sociais: a pesquisa qualitativa em educação: o positivismo, a fenomenologia, o marxismo. 1. ed. São Paulo: Atlas, 1987

WORTMANN, Maria Lúcia. Análises Culturais. In: COSTA, Marisa Vorraber (Org.). Caminhos Investigativos II: outros modos de pensar e fazer pesquisa em educação. 2 ed. Rio de Janeiro: Lamparina, 2007. p. 71-90. 